\title{
Colorectal carcinoma in children and adolescents
}

\author{
Marina D. Mathey, M.D. ${ }^{a}$, Carla L. Pennella, M.D. ${ }^{a}$ and Pedro Zubizarreta, M.D. ${ }^{a}$
}

\begin{abstract}
Although colorectal carcinoma (CRC) is the third most common type of cancer in adults, only $1-4 \%$ of cases are reported in individuals younger than 25-30 years. Its presentation is usually confused with other diseases, leading to significant delays in diagnosis. Given its low incidence, few pediatricians will see a case throughout their practice. However, multiple hereditary syndromes during childhood predispose to CRC. The objective of this review is to provide an update on syndromes predisposing to CRC. Screening indications will be reviewed because an early diagnosis during localized stages is the main prognostic factor. In addition, patient and family genetic counseling tools will be enhanced. In turn, the clinical and histological manifestations and prognostic factors typical of CRC in the pediatric population will be discussed. Although treatment guidelines are extrapolated from the adult experience, therapy guidelines will be summarized here.
\end{abstract}

Key words: colorectal neoplasms, child, adolescent.

http:/ / dx.doi.org/10.5546/ aap.2021.eng.e487

To cite: Mathey MD, Pennella CL, Zubizarreta P. Colorectal carcinoma in children and adolescents. Arch Argent Pediatr 2021;119(5):e487-e498.

\section{INTRODUCTION}

Colorectal carcinoma (CRC) is the third most common malignancy in adults, preceded by lung and breast cancer. Only 1-4\% of CRC cases occur in patients younger than 2530 years. ${ }^{1}$ In pediatrics, it is a rare tumor and is classified under Group XI of the International Classification of Childhood Cancer (ICCC): Other malignant epithelial neoplasms and malignant melanomas.

The annual incidence rate as per the Surveillance, Epidemiology and End Results (SEER) Program is 0.12/1 000000 in the population aged 0-14 years, and increases to $1.78 / 1000000$ between 15 and 19 years of age (Figure 1). 2,3 However, it is the most common primary gastrointestinal malignancy, after liver tumors. ${ }^{4}$

\section{CARCINOGENESIS AND PREDISPOSING HEREDITARY SYNDROMES}

CRC results from the combination of three carcinogenic mechanisms: ${ }^{5}$

- Chromosomal instability: the mutation that inactivates the adenomatous polyposis coli (APC) tumor suppressor gene is the initial event leading to deregulation in E-cadherin homeostasis, with proto-oncogene activation (c-Myc and $K R A S$ ) and tumor suppressor gene inactivation ( $p 53)$. This mechanism is present in 65-70\% of sporadic tumors and in familial adenomatous polyposis.,

- Microsatellite instability (MSI): this is due to a germline mutation in an allele of mismatch repair $(M M R)$ genes, followed by the somatic inactivation of the other allele. These mutations imply length alterations due to nucleotide insertions or deletions in unstable, repeated DNA sequences known as microsatellites. Five reference standard microsatellite markers are used to study them. Highfrequency MSI (MSI-H) is when 2 or more of these markers show length alterations, and is typical of Lynch syndrome. ${ }^{5}$

- CpG is land methylator phenotype: this is caused by the hypermethylation and silencing of tumor suppressor genes (MGMT and MLH1). It is associated with mutations in the BRAF gene and occurs exclusively in $15 \%$ of sporadic CRC cases, where the transcriptional silencing secondary to the aberrant methylation of the MMR hMLH1 gene results in MSI-H. ${ }^{5}$

In pediatrics, $10-30 \%$ of cases have a family history of CRC, all associated 
with predisposing genetic syndromes. ${ }^{1,7}$ These may be classified into 3 groups:

\section{- CRC associated with polyposis:}

- Familial adenomatous polyposis (FAP).

- MUTYH-associated polyposis (MAP).

- Peutz-Jeghers syndrome (PJS).

- Juvenile polyposis syndrome (JPS).

- Juvenile hyperplastic polyposis syndrome.

- Hereditary nonpolyposis CRC:

- Lynch syndrome or hereditary nonpolyposis colorectal cancer (HNPCC).

- Constitutional MMR-deficiency (CMMRD).

- Adenocarcinoma resulting from malignant transformation in inflammatory bowel disease

Complete history taking is critical for screening, with a detailed family history, including the identification of any type of cancer, age at onset, possibly related phenotypic traits, and documentation of histopathological findings. ${ }^{8}$ Table 1 summarizes the diagnostic criteria and screening indications for the most common predisposing syndromes.

\section{A. Familial adenomatous polyposis (FAP)}

FAP has an incidence of $1 / 7000$ individuals. ${ }^{9}$ It is inherited in an autosomal dominant fashion and caused by the mutation that inactivates the
APC tumor suppressor gene. Between $15 \%$ and $20 \%$ of cases correspond to acquired de novo mutations in the $A P C$ gene. ${ }^{9-12}$

A clinical characteristic of FAP is the presence of hundreds of colonic adenomas during preadolescence with malignant transformation at 40-50 years of age. In addition, it occurs with periampullary or ampullary duodenal adenomas. ${ }^{11,12}$

Given its high penetrance, patients have a $100 \%$ risk for CRC at an early age and a cumulative risk for duodenal adenocarcinoma of $10 \%$ at 60 years old. ${ }^{11,13} \mathrm{FAP}$ is less frequently associated with other extracolonic malignancies, such as thyroid carcinoma and hepatoblastoma. Non-malignant, extraintestinal clinical manifestations have been reported, such as congenital hypertrophy of the retinal pigment epithelium (CHRPE), delayed teeth eruption, mandibular osteoma, and multiple fibroid and/ or desmoid tumors. ${ }^{10-12}$

An attenuated form of this syndrome presents with a lower number of polyps (20-100 adenomas, especially in the right colon) and CRC occurs at a later age, known as attenuated familial adenomatous polyposis (AFAP).., 11

Among the pediatric population with CRC, $10 \%$ is associated with mutations in the APC

FIGURE 1. Histogram showing the distribution by age in (A) 550622 patients with CRC diagnosed between 1973 and 2005 , and (B) 159 children and adolescents diagnosed during the same period

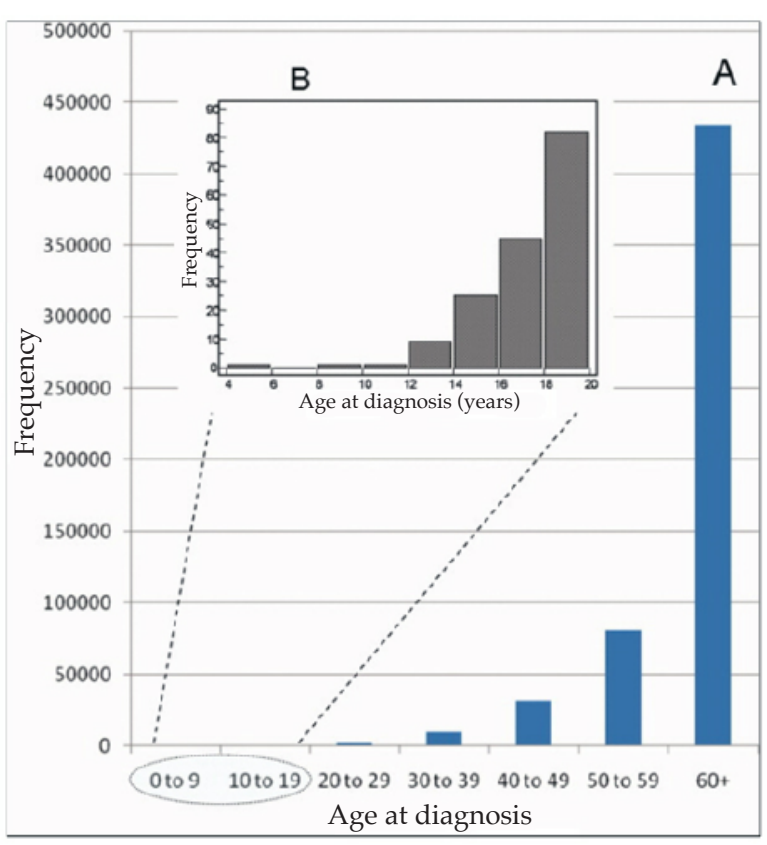


gene. Cases are localized, mostly in the sigmoid colon or rectum. Five-year overall survival (OS) is $59 \%( \pm 12)$, significantly better than that of the rest of the pediatric group $(p=0.085){ }^{3}$

Patients with mutations in the APC gene and their first-degree relatives should be screened with an esophagogastroduodenoscopy (EGD), colonoscopy (COL), and capsule endoscopy as of 10-14 years old. A total colectomy is recommended between 15 and 18 years old, even in asymptomatic patients, to prevent CRC development. ${ }^{11-16}$ After colectomy, patients should undergo annual endoscopic controls given the risk for extracolonic manifestations. For patients with AFAP, endoscopic studies may start as of 18-20 years old. A prophylactic colectomy would not be indicated. ${ }^{16}$

Given the inheritance pattern, $50 \%$ of firstdegree relatives will have the same alteration. ${ }^{10}$

\section{B. MUTYH-associated polyposis (MAP)}

This is an autosomal recessive inherited syndrome caused by a biallelic germline mutation in the MUTYH gene that codes for a DNA repair system.

It is characterized by mild polyposis ( $<100$ colorectal adenomas at diagnosis) and increased risk (93 times higher) for CRC. With a late onset, the mean age at diagnosis of polyposis is adulthood. Also, $58 \%$ of patients will develop CRC. . $214,16,17^{1}$

Patients with more than 100 colonic adenomas should be studied for $A P C$ mutations. If results are negative, the study of the MUTYH gene should continue. If these mutations are not detected, it is recommended to continue with the study of the POLE and POLD1 genes. ${ }^{16}$

A colonoscopy is recommended as of 1820 years old, every 2 years. .,12,14,17 $^{2}$

Table 1. Predisposing hereditary syndromes, diagnostic criteria, and screening recommendations

\begin{tabular}{|c|c|c|}
\hline $\begin{array}{l}\text { Hereditary syndrome } \\
\text { (risk for CRC) }\end{array}$ & Clinical diagnostic criteria & Screening and prophylaxis \\
\hline $\begin{array}{l}\text { FAP } \\
(100 \%)\end{array}$ & $\begin{array}{l}\text { In the absence of molecular diagnosis, suspect: } \\
\text { - } \quad \text { FAP if }>100 \text { adenomatous polyps in between } \\
20 \text { and } 30 \text { years of age. } \\
\text { - } \quad \text { AFAP if }<100 \text { adenomatous polyps in between } \\
40 \text { and } 50 \text { years of age. }\end{array}$ & $\begin{array}{l}\text { - FAP: } 1^{\text {st }} \text { degree relatives: } \\
\text { EGD and COL as of } 10-14 \text { years. } \\
\text { Total colectomy between } 15 \text { and } 18 \text { years. } \\
\text { - AFAP: EGD and COL as of } 18-20 \text { years. } \\
\text { Prophylactic colectomy: would not } \\
\text { be indicated. }\end{array}$ \\
\hline $\begin{array}{l}\text { PJS } \\
(39 \%)\end{array}$ & $\begin{array}{l}\text { One of: } \\
-\quad>2 \text { PJS-like, hamartomatous polyps. } \\
\text { - Any number of PJS-like, hamartomatous polyps } \\
\text { and family history of PJS. } \\
\text { - Characteristic pigment alterations and family } \\
\text { history of PJS. } \\
\text { - Any number of PJS-like, hamartomatous polyps } \\
\text { with characteristic pigment alterations. }\end{array}$ & $\begin{array}{l}\text { EGD, COL, and capsule endoscopy } \\
\text { as of } 8 \text { years old: } \\
\text { - In case of positive findings, repeat } \\
\text { every } 3 \text { years. } \\
\text { - If normal, control as of } 18 \text { years old } \\
\quad \text { every } 3 \text { years. } \\
\text { As of } 25-30 \text { years old: females: } \\
\text { mammography, PAP smear, and periodic } \\
\text { gynecological controls; males: clinical } \\
\text { control and testicular ultrasound. }\end{array}$ \\
\hline $\begin{array}{l}\text { JPS } \\
(38 \%)\end{array}$ & $\begin{array}{l}\text { - At least } 1 \text { of: } \\
\text { - } \quad \text { Multiple juvenile polyps in the digestive tract. } \\
\text { - } \quad \text { Any number of juvenile polyps and family } \\
\text { history of juvenile polyps. }\end{array}$ & $\begin{array}{l}\text { EGD and COL as of } 15 \text { years old } \\
\text { every } 3 \text { years. } \\
\text { Prophylactic colectomy: } \\
\text { polyposis not managed by endoscopy, } \\
\text { bleeding or severe diarrhea, juvenile polyps } \\
\text { with dysplasia, and family history of CRC. }\end{array}$ \\
\hline $\begin{array}{l}\text { LS } \\
(80 \%)\end{array}$ & $\begin{array}{l}\text { Amsterdam II criteria } \\
\text { - } \quad>3 \text { relatives with HNPCC-associated cancer. } \\
\text { Plus all of the following: } \\
\text { - Among them, } 1 \text { first-degree relative. } \\
\text { - Two successive generations affected by the disease. } \\
\text { - In } 1 \text { of them, CRC before age } 50 . \\
\text { - Exclusion of FAP. }\end{array}$ & COL as of $18-20$ years old, every 1-2 years. \\
\hline
\end{tabular}

CRC: colorectal cancer. FAP: familial adenomatous polyposis. AFAP: attenuated familial adenomatous polyposis. PJS: PeutzJeghers syndrome. JPS: juvenile polyposis syndrome. LS: Lynch syndrome.

EGD: esophagogastroduodenoscopy. COL: colonoscopy. HNPCC: hereditary nonpolyposis colorectal cancer. 


\section{Peutz-Jeghers syndrome (PJS)}

The incidence of PJS is $1 / 250000$ individuals. It is an autosomal dominant inherited syndrome caused by a germline mutation in the STK11/LKB1 tumor suppressor gene. In $45 \%$ of cases, no family history is reported. ${ }^{16,18}$

Its phenotypic traits include finger and perioral hyperpigmentation, hamartomatous polyposis in the gastrointestinal tract, small intestine and pancreatic tumors, CRC, and tumor in sex cords. Patients with PJS have a relative risk of $15.2 \%$ for some type of cancer and of $39 \%$ for CRC at any age. ${ }^{12,19}$

Screening is recommended with EGD, COL, and capsule endoscopy at 8 years old. If findings are positive, repeat every 3 years; otherwise, continue with controls as of 18 years old every 3 years. As of 25-30 years old, female patients should undergo a mammography, PAP smear, and periodic gynecological controls; whereas clinical control and testicular ultrasound are recommended for male patients. ${ }^{12,16,18}$

\section{Juvenile polyposis syndrome (JPS)}

The incidence of JPS is 1/100 000-160 000 individuals. ${ }^{20}$ It is an autosomal dominant inherited syndrome with varying degrees of penetrance caused by an inactivating germline mutation in the SMAD4, BMPR1A, and ENG genes. These genes are part of the transforming growth factor- $\beta$ (TGF- $\beta$ ), a tumor suppressor. A family history of hamartomatous polyposis ("juvenile polyps") has been described in 20-50\% of patients. ${ }^{14}$

The clinical presentation of JPS may go from asymptomatic to obstruction, intussusception or acute gastrointestinal bleeding. Extragastrointestinal manifestations include congenital defects, such as midline or cardiac malformations, craniofacial anomalies, and polydactyly. ${ }^{20}$

The mean age at CRC onset is 34 years (range: 15-39 years), and the cumulative risk for CRC is $38 \%$ throughout life. ${ }^{14,16}$

An EGD and COL should be performed as of 15 years old every 3 years. ${ }^{12,16}$ Prophylactic surgery is considered for patients with colorectal polyps that are difficult to manage endoscopically (> 50-100 polyps), severe bleeding or diarrhea, presence of juvenile polyps with dysplasia or a family history of CRC. .12,20 $^{2}$

\section{E. Lynch syndrome (LS) or hereditary nonpolyposis colorectal cancer (HNPCC)}

This is an autosomal dominant inherited syndrome caused by monoallelic mutations in any of the 4 MMR genes: $M L H-1, M S H-2, P M S-2$,

FIGURE 2. Histograms comparing relative frequencies of children, adolescents, and adults with regard to $(A)$ histologic subtypes, (B) tumor sites, (C) stage of disease, and (D) histologic grade
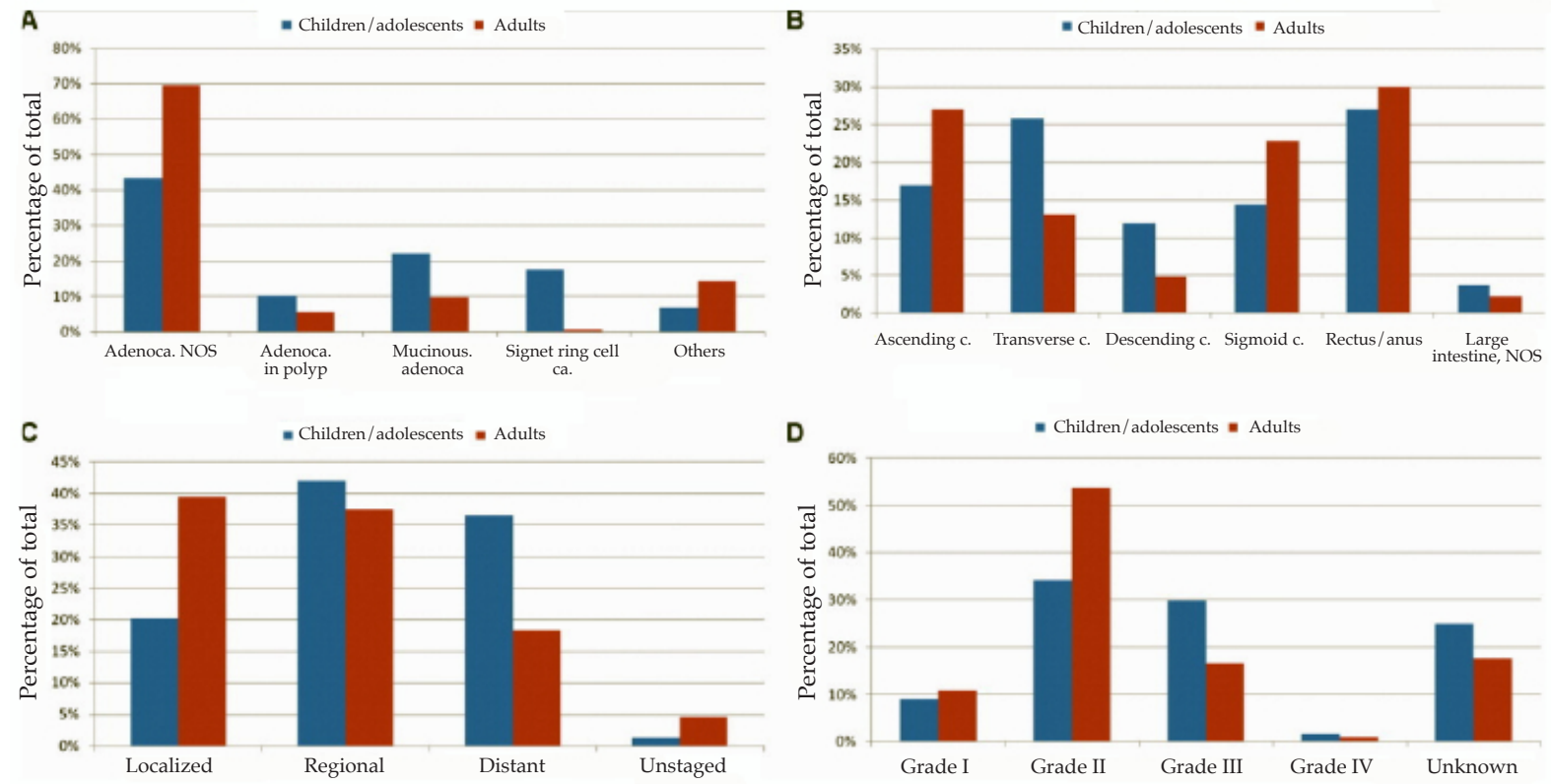

Adenoca: adenocarcinoma. NOS: not otherwise specified. Ca: carcinoma. C: colon.

Adapted from Sultan I, et al. ${ }^{3}$ 
TABLE 2. Staging according to the American Joint Committee on Cancer. 7thed. (TNM and Dukes'staging) and overall survival

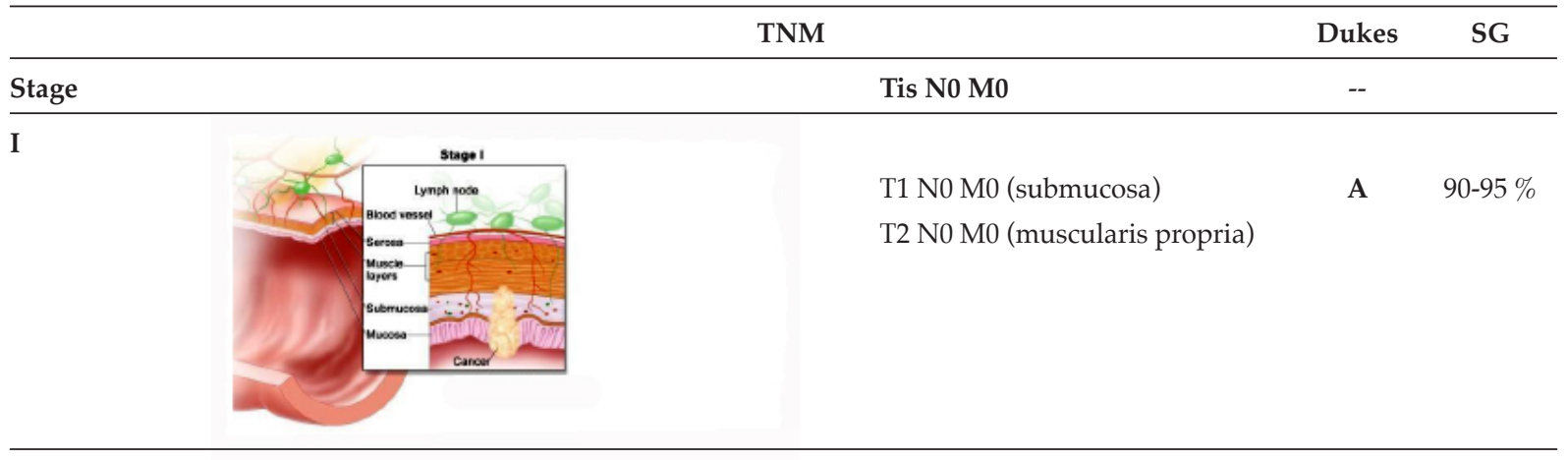

II

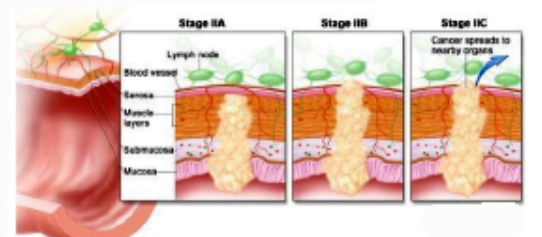

IIA: T3 N0 M0 (invades through

B1

$75-80 \%$ the muscularis propria)

IIB: T4a N0 M0 (visceral peritoneum) B2 $60 \%$

IIC: T4b N0 M0 (contacts other

organs or structures)

III

* N1a: one regional lymph node, N1b: 2-3 regional lymph nodes, N1c: tumor deposits in the subserosa, mesentery or nonperitonealized pericolic or perirectal tissues without regional nodal involvement.

** 4-6 regional lymph nodes.

*** 7 or more regional lymph nodes.

**** Involvement restricted to a single organ or distant lymph nodes.

***** Involvement of more than one organ/ site or peritoneum.

OS: overall survival, AJCC: American Joint Committee on Cancer.

Adapted from Jessup JM, et al. ${ }^{42}$ 
and MSH-6. The pathogenesis of this syndrome is associated with cumulative sequencing errors during DNA replication with the subsequent MSI.

Patients have a predisposition to CRC $(80 \%$ will develop CRC at some point during their life) and endometrial cancer (40\%), among other tumors. ${ }^{4}$ However, there is no association with an increased risk for malignancies during childhood. $^{21}$

Clinical diagnostic criteria (Amsterdam II criteria) are detailed in Table 1.

This entity is responsible for 1-5\% of CRC cases, which presents at a mean age of 45 years. ${ }^{14}$ In general, it is detected in localized stages (78$95 \%$ in stage I and II), 50-60 \% in the right colon, and has a more favorable prognosis. It occurs with a higher incidence of synchronous tumors (CRC within the 6-month period after primary tumor resection) and metachronous tumors (CRC after the 6-month period following primary tumor resection).

MSI detection should be performed in all patients younger than 45 years diagnosed with $\mathrm{CRC}$, as per the Bethesda Guidelines developed by the National Cancer Institute. ${ }^{22}$ A colonoscopy is recommended in patients with LS as of 1820 years old, every 1 or 2 years. ${ }^{23,24}$

If MSI shows an association between CRC and CNS tumors, it is called Turcot syndrome. ${ }^{7}$

\section{F. Constitutional mismatch repair deficiency (CMMRD) syndrome}

CMMRD is caused by a biallelic germline mutation in one of the $4 M M R$ genes with a phenotype different from that of LS: high risk for cancer (blood, CNS, and intestinal) in the first 2 decades of life, multiple adenomatous polyps (10-50), and signs of neurofibromatosis type 1, including café-au-lait skin spots. ${ }^{25}$ Mortality is almost $100 \%$ at 35 years of age. ${ }^{26}$

Screening should start with an annual EGD and COL as of 3-5 years old and, once polyps are identified, they should be repeated every 6 months. Capsule endoscopy may be delayed until 8 years old..$^{25,27,28}$ The screening for other types of cancer should include a head ultrasound at birth and then magnetic resonance imaging every 6 months; laboratory tests and blood count, erythrocyte sedimentation rate, and LDH every 4 months; and annual gynecological and urinary tract ultrasound in adulthood. ${ }^{27}$

If CMMRD is diagnosed, family members should be screened for mutations in the $M M R$ genes. ${ }^{29}$ Siblings have a $25 \%$ chance of developing CMMRD and $50 \%$, of having LS.

\section{G. Inflammatory bowel disease (IBD):} ulcerative colitis and Crohn's disease

The younger the age at IBD diagnosis ( $<25$ years), the higher the risk for CRC. Children

FIGURE 3. Distribution of overall survival at 5 years for 11 patients with predisposing genetic syndromes (100\%) and 15 patients without genetic predisposing factors $(36.5 \%)(p<0.001)$

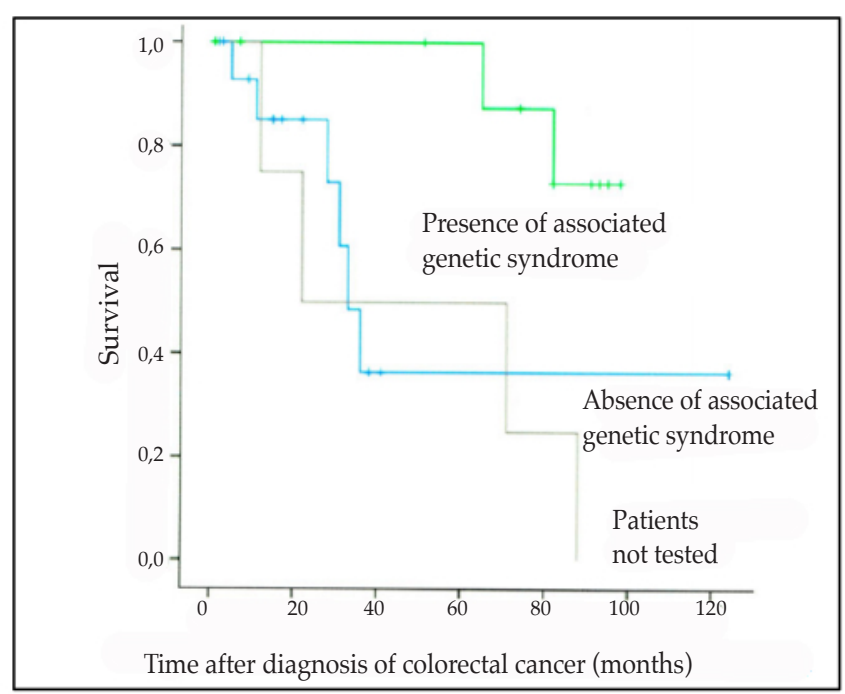

Adapted from Weber M, et al. ${ }^{44}$ 
diagnosed with ulcerative colitis for more than 5 years have a 19 times higher risk than the general population. ${ }^{30}$

\section{CLINICAL PRESENTATION AND DIAGNOSIS}

In pediatrics, CRC has epidemiological characteristics and a clinical and histological presentation different from those of the general population (Figure 2). ${ }^{3}$

Predisposing factors (age, alcohol abuse, smoking, obesity, hypercaloric diet, red meat consumption, and sedentary lifestyle) have been identified in adults, but do not apply in pediatrics. ${ }^{31}$
Also, in children and adolescents, CRC predominates in males (62\%), unlike adults, who show an equivalent sex distribution. ${ }^{3,32}$

Clinical presentation is related to the site of the primary tumor. Tumors located in the cecum and ascending colon (right colon) are usually large masses associated with chronic anemia and late symptoms. Tumors located in the rectum and sigmoid colon (left colon) are related to changes in bowel movements, dyschezia, hematochezia, and anemia. ${ }^{33}$ In pediatrics, almost $80 \%$ of cases occur with iron deficiency anemia, which is the most common symptom, followed by abdominal pain and weight loss. One third of patients show changes in bowel movements and hematochezia.

TABLE 3. Summary of therapeutic recommendations

\begin{tabular}{|c|c|}
\hline TNM stage & Standard of care \\
\hline $\begin{array}{l}\text { I } \\
\text { OS } 90 \%\end{array}$ & - Extensive surgery with anastomosis \\
\hline $\begin{array}{l}\text { II } \\
\text { OS } 72-80 \%\end{array}$ & $\begin{array}{l}\text { - Extensive surgery with anastomosis } \\
\text { - Controversial adjuvant chemotherapy (based on 5-FU). } \\
\text { T4-T3, perforation or obstruction, visceral peritoneum involvement, inadequate resection margins, } \\
\text { poorly differentiated histology. } \\
\text { - Oxaliplatin + fluoropyrimidines are the standard of care. }\end{array}$ \\
\hline $\begin{array}{l}\text { III } \\
\text { OS } \\
\text { IIIA } 60 \%\end{array}$ & $\begin{array}{l}\text { - Extensive surgery with anastomosis } \\
\text { - Neoadjuvant chemotherapy }\end{array}$ \\
\hline $\begin{array}{l}\text { IIIB } 42 \% \\
\text { IIIC } 27 \%\end{array}$ & $\begin{array}{l}\text { - Oxaliplatin + fluoropyrimidines are the standard of care, preferably FOLFOX or regimens including } \\
\text { capecitabine, oxaliplatin. } \\
\text { Patients with }>3 \text { lymph nodes have a worse prognosis. }\end{array}$ \\
\hline IV & $\begin{array}{l}\text { - Surgery is the only potentially curative treatment. It is indicated for: } \\
\text { - Resection with anastomosis of the primary tumor with curative purposes. } \\
\text { - Bypass of the obstruction or bleeding area in selected cases for palliative purposes. } \\
\text { - Resection in selected cases with metastasis to the liver, ovary or a single lung for } \\
\text { curative purposes. } \\
\text { - Palliative radiotherapy } \\
\text { - Palliative chemotherapy: } 1^{\text {st }} \text { line with FOLFOX, FOLFIRI, FOLFOXIRI, CAPOX or FUOX, with or } \\
\text { without bevacizumab (unclear role). }{ }^{47,48,50} \\
\text { 4. Targeted chemotherapy in patients with treatment failure during first-line regimen: } \\
\text { - Cetuximab: does not work in patients with KRAS mutation. } \\
\text { - Ziv-aflibercept: anti-VEGF. } \\
\text { - Ramucirumab: humanized monoclonal antibody that binds to VEGF-2. } \\
\text { - Panitumumab: anti-EGFR, humanized antibody in patients with wild-type KRAS. } \\
\text { - Regorafenib: multiple tyrosine kinase inhibitor, including VEGF. } \\
\text { - Trifluridine and tipiracil (TAS-102): thymidine analog. } \\
\text { - Pembrolizumab: PD- } 1 \text { antibody used in patients with microsatellite instability phenotype (MSI-H) } \\
\text { (4\% of patients in stage IV). } 48,50,51\end{array}$ \\
\hline
\end{tabular}

OS: overall survival, 5-FU: fluorouracil, MSI: microsatellite instability, FOLFOX: leucovorin + fluorouracil + oxaliplatin, FOLFIRI: leucovorin + fluorouracil + irinotecan, FOLFOXIRI: leucovorin + fluorouracil + oxaliplatin + irinotecan, CAPOX: capecitabine + oxaliplatin, FUOX: fluorouracil + oxaliplatin, anti-VEGF: anti-vascular endothelial growth factor, EGFR: epidermal growth factor receptor. 
In advanced cases, intestinal obstruction and perforation may occur, in association with a poor prognosis. The presentation of acute abdomen is more common in pediatrics $(>20 \%) .1,34$

Given that this is an uncommon disease, these symptoms are usually interpreted as other types of conditions and the average diagnostic delay since symptom onset is usually 3 months, compared to 1 month for patients older than 20 years. ${ }^{1,32,35,36}$ It has been hypothesized that such delay may account, in part, for the presentation of more advanced stages. ${ }^{36-38}$

CRC is classified based on the following histologic patterns and grades (pediatric frequency based on data from the SEER Program): ${ }^{3}$

\section{- Histologic patterns}

- Adenocarcinoma not otherwise specified (NOS) $(43 \%)$.

- Mucinous adenocarcinoma (22\%).

- Signet ring cell carcinoma (18\%).

- Others $(17 \%)$.

FiguRE 4. Kaplan-Mayer curves for the estimation of survival of children and adolescents compared according to (A) tumor grade, (B) histologic subtype, and (C) stage of disease
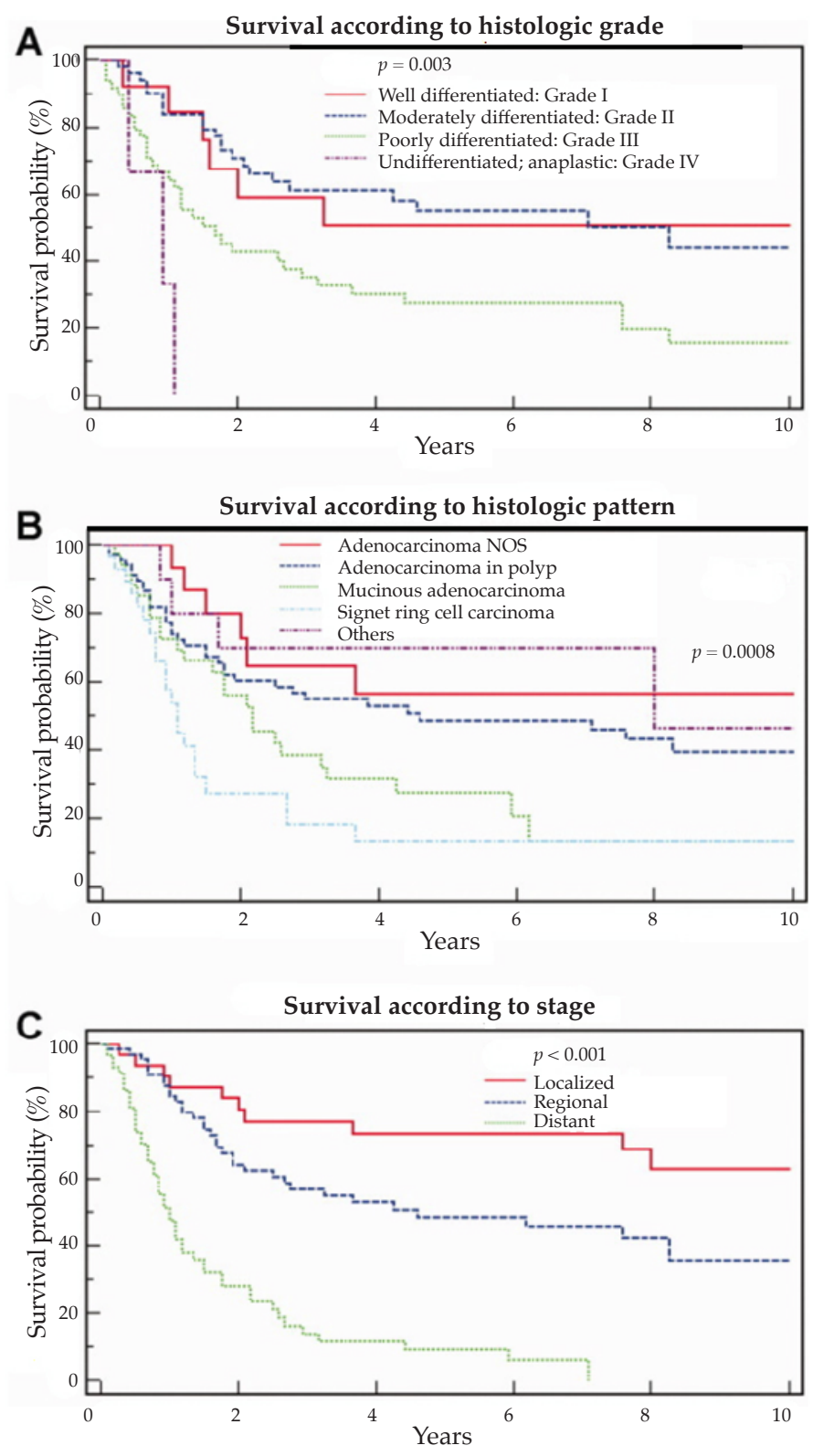

NOS: not otherwise specified. Adapted from Sultan I, et al. ${ }^{3}$ 
- Differentiation grade

- Grade I: well differentiated (9\%).

- Grade II: moderately differentiated (34\%).

- Grade III: poorly differentiated (30\%).

- Grade IV: undifferentiated; anaplastic $(2 \%)$.

- Unknown (25\%).

Low-grade lesions (I-II) without angiolymphatic invasion and with adequate resection margins are classified as favorable histology. ${ }^{35}$

Pediatric patients have a higher incidence of mucinous and signet ring cell patterns, in addition to poorly differentiated or undifferentiated grades. ${ }^{3,34}$ Given the fact that this is a rare disease in pediatrics, histology has not demonstrated a prognostic value. ${ }^{35}$

\section{STAGING}

Only $19 \%$ of children and adolescents have localized disease, and twice as much possibilities of developing distant metastasis compared to adults. ${ }^{1,3}$ Such characteristic restricts surgical possibilities, the main option for a cure.

The Rare Tumors in Pediatric Age (TREP, for its Italian acronym) project guidelines recommend an abdominal ultrasound, EGD, and
COL as initial tests. Patients with predisposing genetic syndromes should also undergo a capsule endoscopy, based on the indications. ${ }^{39}$

Recommended initial staging tests include a computed tomography (CT) of the chest, abdomen, and pelvis, and a bone scan with Tc99. The TREP guidelines recommend using positron emission tomography. ${ }^{31,39,40}$

Tumor markers (carcinoembryonic antigen [CEA] and carbohydrate antigen 19-9 [CA 199]) may be useful to assess treatment response in patients with metastasis and to monitor for relapses. ${ }^{41}$

The guidelines established by the American Joint Committee on Cancer (AJCC, $7^{\text {th }}$ edition) provide the most commonly used CRC staging combining the TNM system and Dukes' prognostic stages (Table 2). ${ }^{42}$ In pediatrics, $18.4 \%$ of patients have Dukes B; $55.3 \%$, Dukes C; and $26.3 \%$, Dukes D; none was classified as Dukes A. ${ }^{1}$

In young patients, the most common metastasis sites are the peritoneum $(34 \%)$, liver $(32 \%)$, lungs $(9 \%)$, ovaries $(7 \%)$, and bones $(7 \%)$. This pattern is different from that observed in adults, in whom the most common metastasis sites are the liver (30-70\%), lungs (20-40\%), and bones $(5-10 \%))^{1,32}$

FIGURE 5. Estimated survival graphs comparing ( $A$ ) children, adolescents, and adults ( $p<0.001$, log-rank test), (B) only children and adolescents, and (C) only adults during 3 periods
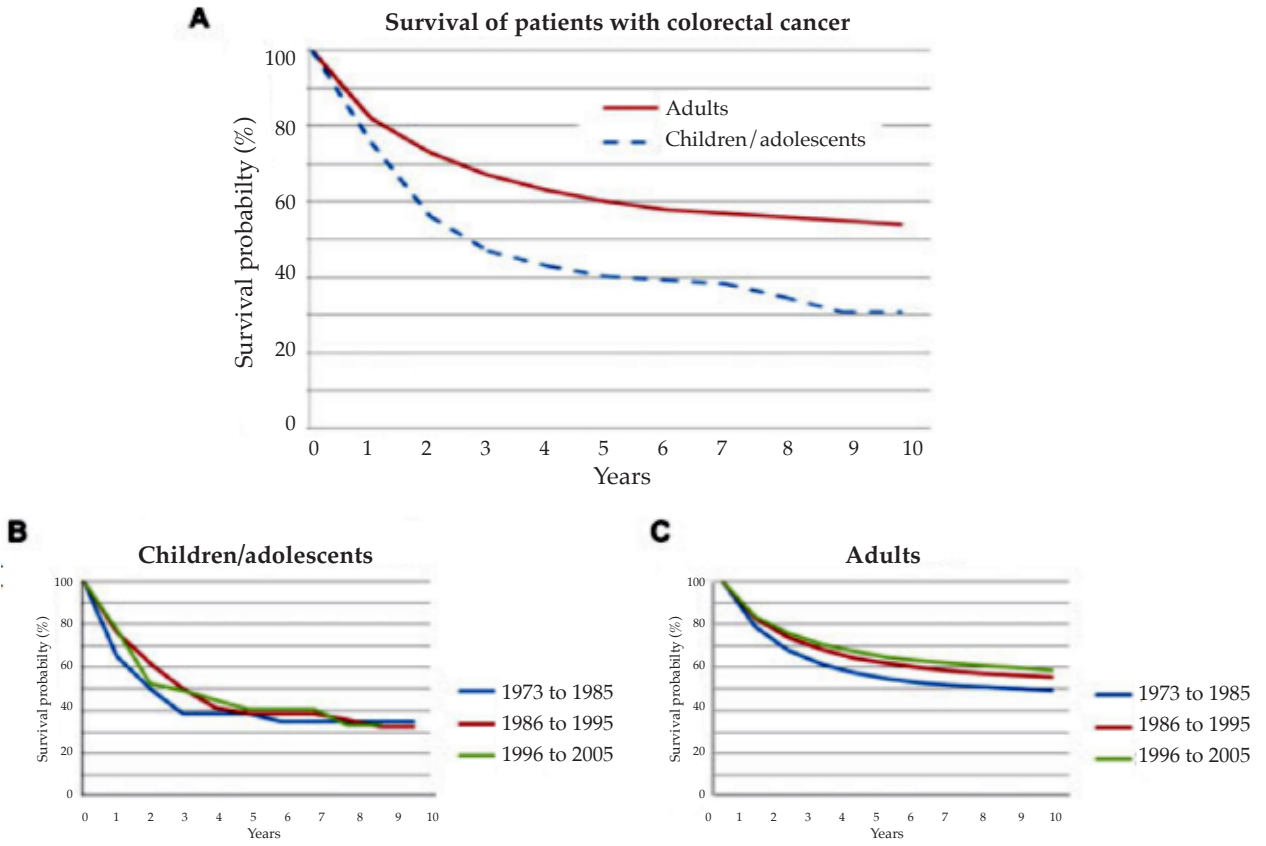


\section{PROGNOSTIC FACTORS AND SURVIVAL}

Patients with HNPCC have a better prognosis than those with sporadic disease, regardless of the initial tumor staging. ${ }^{5}$ Mork et al., ${ }^{43}$ studied a cohort of 193 patients younger than 35 years and identified that $35 \%$ of patients had predisposing hereditary syndromes: patients without hereditary syndromes were more prone to developing left-sided tumors, metastasis, and an unfavorable histology. Weber et al., ${ }^{44}$ also evidenced that patients with predisposing syndromes (mainly HNPCC) had a less aggressive condition and a better survival (Figure 3).

In the pediatric population, unfavorable prognostic factors include histologic grade IIIIV, mucinous or signet ring cell pattern, and an advanced initial stage with regional and/ or distant invasion. In patients who undergo a complete resection, the identification of tumor invasion of the serosa and the presence of positive lymph nodes are independent factors of poor prognosis (Figure 4). ${ }^{1,3}$

In pediatrics, according to the SEER Program data, estimated OS at 5 and 10 years is $40 \%$ (4.2) and $31 \%$ (4.4), respectively..$^{2,3}$ Event-free survival (EFS) at 10 years is $17.7 \%$ (5.1). ${ }^{31}$ These values are different in adults, whose OS at 5 and 10 years is $60 \%(0.1)$ and $54 \%(0.1)$, respectively $(p<0.001)$ (Figure 5). ${ }^{3}$

OS at 5 years in patients with stage M1a is $20.6 \%$ versus $7.7 \%$ in those with stage M1b. ${ }^{32,41}$

\section{TREATMENT}

The recommendations made for children and adolescents are adapted from the experience in adults. ${ }^{39}$

\section{- Surgery}

Surgery is the mainstay of treatment and should be radical. Without a complete surgical resection, the cure cannot be achieved. ${ }^{39}$ It may even be curative in patients with resectable liver or lung metastases. Resection margins need to be $\geq 5 \mathrm{~cm}$ of normal intestine to prevent anastomotic recurrence. At least 12 negative lymph nodes should be examined to define disease stage as N0. ${ }^{31}$ The peritoneal surface should be examined, including the renal fascia and the diaphragm. All peritoneal lymph nodes should be resected.

In pediatrics, CRC is rarely the initial suspected diagnosis. If surgery is oncologically inappropriate, a revision surgical exploration is indicated to check margins and the necessary lymph node examination.

\section{- Chemotherapy}

The indication of an adjuvant treatment depends on the initial stage, and the guidelines for adult patients are applied. ${ }^{39}$

Patients in stage I have a survival of $90 \%$ at 5 years only with surgery, and a close monitoring is recommended, without the need for adjuvant chemotherapy.

The role of adjuvant chemotherapy is not clear in patients in stage II, and does not appear to improve OS by more than $5 \%$. Most children and adolescents with stage II disease show unfavorable prognostic factors, so adjuvant chemotherapy should be considered. ${ }^{31,45}$

Chemotherapy has a clear benefit in stage IIIIV cases (nodal involvement and / or metastasis). ${ }^{39}$ Management is controversial. Chemotherapy based on 5-fluorouracil and folinic acid (5-FU$\mathrm{LV}$ ) is performed, in association with other agents with proven usefulness: capecitabine, oxaliplatin, and irinotecan. ${ }^{31}$

\section{- Targeted therapies}

Targeted therapy has demonstrated to be beneficial for some patients, mainly those in advanced stages (III-IV). The therapeutic agents most studied for CRC include bevacizumab, pembrolizumab, cetuximab, panitumumab, bortezomib, and gefitinib. ${ }^{31,46-51}$

\section{- Radiotherapy}

The role of radiotherapy is limited to postsurgery use in patients with rectal cancer, combined with chemotherapy with 5-FU. ${ }^{39}$ In advanced cases (stage T4, local perforation or obstruction), radiotherapy may be used before the surgery to reduce the probability of recurrence after the procedure or to allow for less invasive surgical procedures.

Table 3 shows a summary of therapeutic recommendations.

\section{CONCLUSION}

In pediatrics, CRC depicts its own biological features, different from those observed in adults, and represents a specific sub-group of rare tumors in children.

Given the low incidence of CRC in this age group, we believe it is critical to conduct a network collaboration with specialized adult care facilities in order to establish a comprehensive approach, with adequate and timely treatments under the guidance of CRC experts.

CRC has shown a clear association with 
family cancer syndromes, whose manifestations, although mostly develop in adulthood, could be prevented and managed in a timely manner through an early and adequate screening. In turn, it is important for pediatricians to be able to provide adequate genetic counseling to the patient's family.

\section{REFERENCES}

1. Kaplan M, Isikdogan A, Gumus M, Arslan U, et al. Childhood, adolescents, and young adults $(\leq 25 \mathrm{y})$ colorectal cancer: study of Anatolian Society of Medical Oncology. J Pediatr Hematol Oncol. 2013; 35(2):83-9.

2. Brench I, Kaatsch P. Epidemiology. In Schneider D, Brecht I, Olson T, Ferrari A (eds). Rare tumors in children and adolescents. Berlin, Heidelberg: Springer-Verlag; 2012. Pages.43-61.

3. Sultan I, Rodriguez-Galindo C, El-Taani H, Pastore G, et al. Distinct features of colorectal cancer in children and adolescents: a population-based study of 159 cases. Cancer. 2010; 116(3):758-65.

4. Olson T, Schneider D, Brecht I, Ferrari A. Rare Tumors: A Different Perspective on Oncology. In: Schneider D, Brecht I, Olson T, Ferrari A (eds). Rare tumors in children and adolescents. Berlin, Heidelberg: Springer-Verlag;2012. Pages.3-13.

5. Gryfe R, Kim H, Hsieh E, Aronson M, et al. Tumor microsatellite instability and clinical outcome in Young patients with colorectal cancer. NEnglJMed. 2000;342(2):6977.

6. Tariq K, Ghias K. Colorectal cancer carcinogenesis: a review of mechanisms. Cancer Biol Med. 2016; 13(1):120-35.

7. SingerG,Hoellwarth ME. Colorectal carcinomas in children: an institutional experience. Pediatr Surg Int. 2012;28(6):5915.

8. Lynch HT, de la Chapelle A. Hereditary colorectal cancer. N Engl J Med. 2003; 348(10):919-32.

9. Vasen HF, Möslein G, Alonso A, Aretz S, et al. Guidelines for the clinical management of familial adenomatous polyposis (FAP). Gut. 2008; 57(5):704-13.

10. Septer S, Lawson CE, Anant S, Attard T. Familial adenomatous polyposis in pediatrics: natural history, emerging surveillance and management protocols, chemopreventive strategies, and areas of ongoing debate. Fam Cancer. 2016; 15(3):477-85.

11. Hyer W, Cohen S, Attard T, Vila-Miravet V, et al. Management of Familial Adenomatous Polyposis in Children and Adolescents: Position Paper From the ESPGHAN Polyposis Working Group.JPediatr Gastroenterol Nutr. 2019; 68(3):428-41.

12. Achatz MI, Porter CC, Brugières L, Druker H, et al. Cancer Screening Recommendations and Clinical Management of Inherited Gastrointestinal Cancer Syndromes in Childhood. Clin Cancer Res. 2017; 23(13):e107-14.

13. Möslein G, Pistorius S, Saeger HD, SchackertHK. Preventive surgery for colon cancer in familial adenomatous polyposis and hereditary nonpolyposis colorectal cancer syndrome. Langenbecks Arch Surg. 2003; 388(1):9-16.

14. Bertario L, Signoroni S. Gastrointestinal Cancer Predisposition Syndromes. In: Schneider DT, Brecht IB, Olson TA, Ferrari A (eds). Rare tumors in children and adolescents. Berlin Heidelberg: Springer-Verlag; 2012. Pages.255-62.

15. Vitellaro M, Ferrari A, Trencheva K, Sala P, et al. Is laparoscopic surgery an option to support prophylactic colectomy in adolescent patients with Familial
Adenomatous Polyposis (FAP)? Pediatr Blood Cancer. 2012; 59(7):1223-8.

16. Guillén-Ponce $C$, Serrano R, Sánchez-Heras AB, Teulé A, et al. Clinical guideline seom: hereditary colorectal cancer. Clin Transl Oncol. 2015; 17(12):962-71.

17. Nieuwenhuis MH, Vogt $S$, Jones $N$, Nielsen $M$, et al. Evidence for accelerated colorectal adenoma-carcinoma progression in MUTYH-associated polyposis? Gut. 2012; 61(5):734-8.

18. Latchford A, CohenS, AuthM,ScaillonM, etal.Management of Peutz-Jeghers Syndrome in Children and Adolescents: A Position Paper From the ESPGHAN Polyposis Working Group. J Pediatr Gastroenterol Nutr. 2019; 68(3):442-52.

19. Giardiello FM, Trimbath JD. Peutz-Jeghers syndrome and management recommendations. Clin Gastroenterol Hepatol. 2006; 4(4):408-15.

20. IshidaH, IshibashiK, Iwama T.Malignant tumorsassociated with juvenile polyposis syndrome in Japan. Surg Today. 2018; 48(3):253-63.

21. HeathJA, ReeceJC, Buchanan DD, Casey G, etal. Childhood cancers in families with and without Lynch syndrome. Fam Cancer. 2015; 14(4):545-51.

22. Umar A, Boland R, Terdiman J, Syngal S, et al. Revised Bethesda Guidelines for hereditary nonpolyposis colorectal cancer (Lynch syndrome) and microsatellite instability. J Natl Cancer Inst. 2004; 96(4):261-8.

23. Vasen H, Blanco I, Aktan-Collan K, Gopie JP, et al. Revised guidelines for the clinical management of Lynch syndrome (HNPCC) recommendations by a group of European experts. Gut. 2013; 62(6):812-23.

24. Seppälä TT, Pylvänäinen K, Mecklin JP. Uptake of genetic testing by the children of Lynch syndrome variant carriers across three generations. Eur J Hum Genet. 2017;25(11):123745.

25. Aronson M, Gallinger S, Cohen Z, Cohen S, et al. Gastrointestinal Findings in the Largest Series of Patients With Hereditary Biallelic Mismatch Repair Deficiency Syndrome: Report from the International Consortium. Am J Gastroenterol. 2016; 111(2):275-84.

26. Antelo M, Milito D, Rhees J, Roca E, et al. Pitfalls in the diagnosis of biallelic PMS2 mutations. Fam Cancer. 2015; 14(3):411-4.

27. Durno C, Aronson M, Tabori U, Malkin D, et al. Oncologic surveillance for subjects with biallelic mismatch repair gene mutations: 10 year follow-up of a kindred. Pediatr Blood Cancer. 2012; 59(4):652-6.

28. Levi Z, Kariv R, Barnes-Kedar I, Goldberg Y, et al. The gastrointestinal manifestation of constitutional mismatch repair deficiency syndrome: from a single adenoma to polyposis-like phenotype and early onset cancer. Clin Genet. 2015; 88(5):474-8.

29. Westdorp H, Kolders S, Hoogerbrugge N, de Vries IJ, et al. Immunotherapy holds the key to cancer treatment and prevention in constitutional mismatch repair deficiency (CMMRD) syndrome. Cancer Lett. 2017; 403:159-64.

30. Peneau A, Savoye G, Turck D, Dauchet L, et al. Mortality and cancer in pediatric-onset inflammatory bowel disease: a population-based study. Am J Gastroenterol. 2013; 108(10):1647-53.

31. GoldbergJ, Furman W. Management of colorectal carcinoma in children and young adults. J Pediatr Hematol Oncol. 2012; 34(Suppl 2):S76-9.

32. Hill D, Furman W, Billups C, Riedley S, et al. Colorectal carcinomain childhood and adolescence: a clinicopathologic review. J Clin Oncol. 2007; 25(36):5808-14.

33. Al-Tonbary Y, Darwish A, El-Hussein A, Fouda A. Adenocarcinoma of the colon in children: case series and mini-review of the literature. Hematol Oncol Stem Cell Ther. 
2013; 6(1):29-33.

34. Kaplan MA, Ozaydin S, Yerlikaya H, Karaagac M, et al. Clinicopathologic and prognostic differences between three different age groups (child/adolescent, young adults, and adults) of colorectal cancer patients: a multicentre study. Oncol Res Treat. 2019; 42(10):516-22.

35. Shehata B, ShulmanS. Pathology and Differential Diagnosis. In:Schneider DT, Brecht IB, Olson TA, Ferrari A (eds). Rare tumors in children and adolescents. Berlin, Heidelberg: Springer-Verlag 2012.Pages.245-54.

36. Chantada G, Perelli V, García Lombardi M, Amaral D, et al. Colorectal carcinoma in children, adolescents, and young adults. J Pediatr Hematol Oncol. 2005; 27(1):39-41.

37. KarnakI, Ciftci A, SenocakM, Büyükpamukçu N. Colorectal carcinoma in children. J Pediatr Surg. 1999; 34(10):1499-504.

38. Lamego C, Torloni H. Colorectal adenocarcinoma in childhood and adolescent. Report of 11 cases and review of the literature. Pediatr Radiol. 1989; 19(8):504-8.

39. Indini A, Bisogno G, Cecchetto G, Vitellaro M, et al. Gastrointestinal tract carcinoma in pediatric and adolescent age: the TREP project experience. Pediatr Blood Cancer. 2017; 64(12):1-8.

40. Kunawudhi A, SereeborwornthanasakK, Promteangtrong C, Siripongpreeda B, et al. Value of FDG PET/ContrastEnhanced CT in Initial Staging of Colorectal Cancer Comparison with Contrast-Enhanced CT. Asian Pac JCancer Prev. 2016; 17(8):4071-5.

41. Ferrari A, Casanova M, Massimino M, Sultan I. Peculiar features and tailored management of adultcancers occurring in pediatricage. Expert Rev Anticancer Ther. 2010;10(11):183751.

42. JessupJM, Goldberg RM, Asare EA, et al. Colon and rectum. In: Amin MB, Edge SB, Greene FL, Byrd F, et al. (eds). AJCC Cancer Staging Manual. $8^{\text {th }}$ ed. New York, NY: Springer, 2017.Pages.251-74.
43. Mork M, You Y, Ying J, Bannon S, et al. High prevalence of hereditary cancer syndromes in adolescents and Young adults with colorectal cancer. JClin Oncol. 2015;33(31):35449.

44. Weber M, Schneider D, Offenmüller S, Kaatsch P, et al. Pediatric Colorectal Carcinoma is Associated With Excellent Outcome in the Context of Cancer Predisposition Syndromes. Pediatr Blood Cancer. 2016; 63(4):611-7.

45. Zhou Z, Wu X, Wang R, Li L, et al. Optimal use of adjuvant chemotherapy in stage II colorectal cancer. Int J Colorectal Dis. 2011; 26(7):867-73.

46. Hurwitz H, Fehrenbacher L, Novotny W, Cartwright $\mathrm{T}$, et al. Bevacizumab plus irinotecan, fluorouracil, and leucovorin for metastatic colorectal cancer. $N$ Engl J Med. 2004; 350(23):2335-42.

47. Saltz L, Clarke S, Díaz-Rubio E, Scheithauer W, et al. Bevacizumab in combination with oxaliplatin-based chemotherapy as first-line therapy in metastatic colorectal cancer: a randomized phase III study. J Clin Oncol. 2008; 26(12):2013-9.

48. Marcus L, Lemery SJ, Keegan P, Pazdur R. FDA Approval Summary: Pembrolizumab for the Treatment of Microsatellite Instability-High Solid Tumors. Clin Cancer Res. 2019; 25(13):3753-8.

49. Saltz L. Adjuvant therapy for colon cancer. Surg Oncol Clin N Am. 2010; 19(4):819-27.

50. Salman P, Panay S, Fernández R, Mahave M, Soza-Ried C. Evidence of response to pembrolizumab in a patient with Lynch syndrome-related metastatic colon cancer. Onco Targets Ther. 2018; 11:7295-300.

51. Benson A $3^{\text {rd }}$, Venook A, Cederquist L, Chan E, et al. Colon Cancer, Version 1.2017, NCCN Clinical Practice Guidelines in Oncology. J Natl Compr Canc Netw. 2017; 15(3):370-98. 